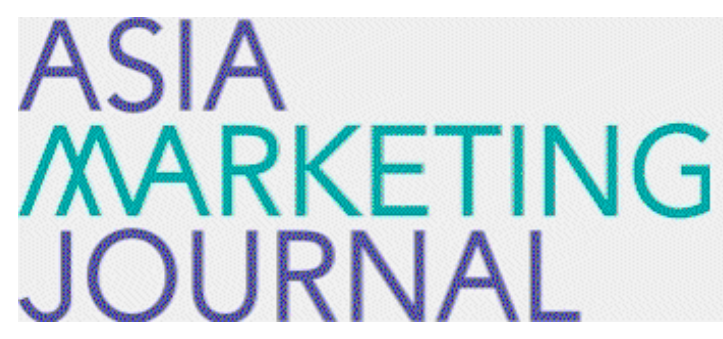

ASIA MARKETING JOURNAL

Volume 18 | Issue 1

Article 2

4-30-2016

\title{
Exploring the Customization Decision Support System Using Waypoint Solutions
}

Akinori Ono

Kiyokazu Matsuura

Seiji Endo

Nakagawa

Follow this and additional works at: https://amj.kma.re.kr/journal

Part of the Marketing Commons

\section{Recommended Citation}

Ono, Akinori; Matsuura, Kiyokazu; Endo, Seiji; and Nakagawa (2016) "Exploring the Customization Decision Support System Using Waypoint Solutions," Asia Marketing Journal: Vol. 18 : Iss. 1 , Article 2. Available at: https://doi.org/10.15830/amj.2016.18.1.23

This Article is brought to you for free and open access by Asia Marketing Journal. It has been accepted for inclusion in Asia Marketing Journal by an authorized editor of Asia Marketing Journal. 


\title{
Exploring the Customization Decision Support System Using Waypoint Solutions*
}

\author{
Akinori Ono** \\ Kiyokazu Matsuura*** \\ Seiji Endo***** \\ Yuji Nakagawa***
}

\begin{abstract}
Product customization has been popular since Internet shopping began. Many firms have introduced customization configuration systems, allowing customers to choose a wide range of product attributes, attracting them to participate in the shopping process, and increasing customer satisfaction. Paradoxically, the attribute-by-attribute $(\mathrm{AbA})$ choice in the customization process requires a high-information processing load resulting in shopper confusion. To reduce this confusion, the CvSS (customization via starting solution) system has recently been developed. However, this system provides solution support only for the starting point of the configuration process. Thus, in this study, the authors proposes the CvWS (Customization via Waypoint Solutions) system, which would greatly reduce the customer effort needed to complete the configuration process by using a novel approach to solve the nonlinear knapsack problem. The newly proposed system is theoretically compared with the AbA customization as well as the CvSS system. Also, its feasibility is discussed in the context of the nonlinear multiconstraint knapsack problem.
\end{abstract}

Key words: product customization, starting solutions, waypoint solution, knapsack problem

\footnotetext{
* The authors would like to express their deepest gratitude to 2015 ICAMA Product Development Track Co-chairs, Professor Tomoko Kawakami (Waseda University, Japan), Professor Subin Im (Yonsei University, Korea), and Professor Yonggui Wang (Foreign Economic and Trade University, China). The authors also thank the Editor-in-Chief of the Asia Marketing Journal, Professor Jaihak Chung (Sogang University, Korea) and two anonymous reviewers for their useful suggestions. This article was supported by JSPS KAKENHI Grant \#16K03940.

** Keio University (akinori@keio.jp)

*** Kansai University

**** Tokai University

****** Kansai University
} 


\section{Purpose}

Today, more and more firms offer product customization through their websites to their customers. Product customization refers to customers ordering a product with a certain product configuration or a combination of product attributes that match their individual needs among various product configurations. Product customization systems provide a wide variety of products at lower prices than ever before and are preferred over standardized products because of their advantages in matching individual customers' needs. For example, previously when purchasing a car, customers would visit dealers, shop around their auto parks, and select a car out of a limited number of choices before deciding which one to buy. However, in recent years, more and more customers have been able to "build' their own cars online.

The key advantage of customization is that it provides a wide variety of products for various customers' needs (cf. Ogawa and Piller 2006). If a customization system offers two levels for each of two attributes (body color and engine, for example), then the possible combinations of the product attributes are only $4\left(=2^{2}\right)$. However, if the system allows customers to choose from four levels for each of four attributes (color, engine, wheels, and seats, for example), then the possible combinations are $256\left(=4^{4}\right)$. In this manner, even though the number of attributes and their levels increase only slightly, there is an inordinate increase in the variety of final possible product combinations (Kumar 2004). Using the customization system, automakers and dealers have succeeded in providing a wider variety of products online than has been hitherto been possible to stock in their dealerships.

However, while customization has an advantage in providing a wide variety of choices, too many choices in a customization system can lead to mass confusion (cf. Huffman and Kahn 1998; Simonson 2005; Dellaet and Stremersch 2005; Hildebrand, Häubl, and Herrmann 2014), as it requires greater effort to select one option out of the various options available in each of the multiple product attributes. Therefore, in recent years, customizers have replaced the attributeby-attribute (AbA) customization system with the CvSS (customization via starting solution) system, in which they ask their customers first to select a particular product from a limited number of products as a starting solution and then refine this starting solution and create their customized product by changing some of the attributes (Hildebrand, Häubl, and Herrmann 2014).

By offering particular combinations at the beginning of the customization process, CvSS firms succeed in decreasing the information load for customers when choosing and ordering a particular combination of attributes. Customers need to change only a few attributes that they wish to alter based on the selected starting solution. 
It should be noted, however, that in the CvSS system, firms only assist their customers at the starting point of the customization process. Customers may want to use not only starting solutions but also waypoint solutions suggested by the firm as a reference after they have changed the level of one or more attributes of a selected starting solution. Therefore, in this paper, we propose a new customization system called the CvWS (customization via waypoint solutions) system, which is superior to the existing CvSS (customization via starting solutions) system.

It has been found that with the CvSS system, even though a set of starting solutions could be randomly suggested to customers, customer satisfaction with the customization experience is higher than with the AbA customization system, but customer satisfaction did not differ among various CvSS systems with different sets of proposed starting solutions (Hildebrand, Häubl, and Herrmann 2014). In contrast, as for CvWS, waypoint solutions are more likely to be optimized and suggested to customers who have struggled to choose from a range of product attributes, feel generally confused by the process, or need assistance. In such instances, how can firms suggest optimal solutions to customers? We also discuss the issue by viewing this simultaneous optimization problem of suggested multiattribute solutions as a multiobjective nonlinear "knapsack problem" and propose that our improved surrogate constraint method can be utilized to address the issue.

\section{Literature}

As discussed in previous research, the highvariety strategy, including mass customization, can induce confusion, resulting in customers being burdened with a complex choice task due to the daunting number of options. Huffman and Kahn (1998) investigated how firms implement the high-variety strategy while allowing their customers to participate easily in the complex shopping process at the same time, and found that sales assistants can reduce the customers' burden and contribute to increased satisfaction with the complex customization shopping process. Huffman and Kahn's research were followed by many studies regarding mass confusion in this context (e.g., Hoch, Bradlow, and Wansink 1999; Liechty, Ramaswamy, and Cohen 2001; Delleart and Stremersch 2005; Randall, Terwiesch, and Ulrich 2005; Kurniawan, So, and Tseng 2006).

Unlike Huffman and Kahn (1998), Liechty, Ramaswamy, and Cohen (2001) utilized a website for evaluating customers' favorable behavior via a "choiceboard" for customization configuration, and investigated whether the integration of firmbase information and individual customer information would be beneficial for improving a customization configuration process.

Focusing on firms' support to their customers' customization process, Kurniawan, So, and Tseng (2006) also utilized an experimental website and 
investigated the degree of satisfaction. The results showed that customers were more satisfied with the attribute-based shopping process than the alternative-based shopping process and, in both cases, understanding and support of customers' needs throughout the process were vital in reducing customer effort and, therefore, increasing customer satisfaction with the customized shopping process.

On the other hand, Delleart and Stremersch (2005) investigated the relationship between complexity and utility. The results showed that the complexity of customization configuration reduced the utility of customized goods. However, the impact of complexity on utility was lower if the degree of customer expertise was higher.
It also implies that customers' needs help to complete the customization process if they have low knowledge and skill levels.

More recently, Hildebrand, Häubl, and Herrmann (2014) defined the "CvSS (customization via starting solutions) system" as a new customization configuration process in which customers select a product among several "starting solutions" offered by the firm, then change the levels of some attributes based on their preferences. In the CvSS system, firms assist their customers' customization process by offering several final products as "starting solutions" at the outset to simplify the entire shopping process. Therefore, Hildebrand, Häubl, and Herrmann hypothesized that the CvSS system is superior to the "AbA

$\langle$ Table 1〉 Three Existing Systems

\begin{tabular}{|c|c|c|}
\hline System & Description & Reference \\
\hline $\begin{array}{l}\text { Alternative-based } \\
\text { (non-customization) } \\
\text { shopping system }\end{array}$ & $\begin{array}{l}\text { The shopping system in which customers choose an alternative } \\
\text { out of limited numbers of ready-made products offered by the } \\
\text { firm. }\end{array}$ & \\
\hline $\begin{array}{l}\text { AbA } \\
\text { (attribute by attribute) } \\
\text { customization system }\end{array}$ & $\begin{array}{l}\text { The customization system in which customers choose product } \\
\text { attributes one by one to build their own products. It is shown } \\
\text { that customers tend to choose an intermediate (compromise) } \\
\text { option significantly more often when they customize a product } \\
\text { using the AbA method than they do with the alternative-base } \\
\text { shopping method. The AbA customization system leads to a } \\
\text { lower level of experienced difficulty, greater satisfaction, and } \\
\text { higher willingness to purchase customized products than the } \\
\text { alternative-base shopping method. }\end{array}$ & $\begin{array}{l}\text { Valenzuela, } \\
\text { Dhar, and } \\
\text { Zettelmeyer } \\
\text { (2009) }\end{array}$ \\
\hline $\begin{array}{l}\text { CvSS } \\
\text { (customization via } \\
\text { starting solutions) } \\
\text { system }\end{array}$ & $\begin{array}{l}\text { The customization system in which customers change any } \\
\text { product attributes of an already offered product. It is proposed } \\
\text { that a two-stage approach would reduce customers' cognitive } \\
\text { effort associated with product customization, promote mental } \\
\text { simulation in relation to product use, motivate the purchase of a } \\
\text { more feature-rich product and, thus, higher-priced product, and } \\
\text { lead to greater satisfaction with self-designed products. }\end{array}$ & $\begin{array}{l}\text { Hildebrand, } \\
\text { Häubl, and } \\
\text { Herrmann } \\
(2014)\end{array}$ \\
\hline
\end{tabular}


(attribute-by-attribute) customization system" (Valenzuela, Dhar, and Zettelmeyer 2009). The results showed that customer satisfaction with the CvSS system was higher than that with AbA system because less effort was required. Also, no significant differences were found between the degrees of customer satisfaction in the cases of randomly offered starting solutions and optimally offered starting solutions.

Note that the CvSS system can be regarded as the integration of an alternative-based shopping phase in the beginning and an attributebased shopping phase during the rest of the process. Because the firm just offers alternativebased choices during the first process, the CvSS system would not drastically reduce customers' tedious configuration workload. To reduce this workload, there is room for developing a new customization system that offers a different form of integration of alternative-based and attributebased shopping processes.

\section{Customization via Waypoint Solutions}

In this section we will discuss what our new customization model is and why the model is superior to alternative models. First of all, Figure 1 shows the non-customization, ordinary purchasing system, namely, the alternative-based shopping process. For example, some customers for a personal computer may choose one of a selection of pre-built personal computers. Note that customers choose a combination of $Z_{1}-Z_{n}$ among limited numbers of combinations offered by the firm, where $Z_{1}-Z_{n}$ represent levels of product attributes 1 to $n$ (for example, CPU clock rate, memory capacity, and hard disk space of a personal computer).

In contrast, customization systems are shown in Figures 2 to 4. Figure 2 represents the AbA (attribute-by-attribute) customization system

〈Figure 1〉 Non=Customization, Ordinary Purchasing Process

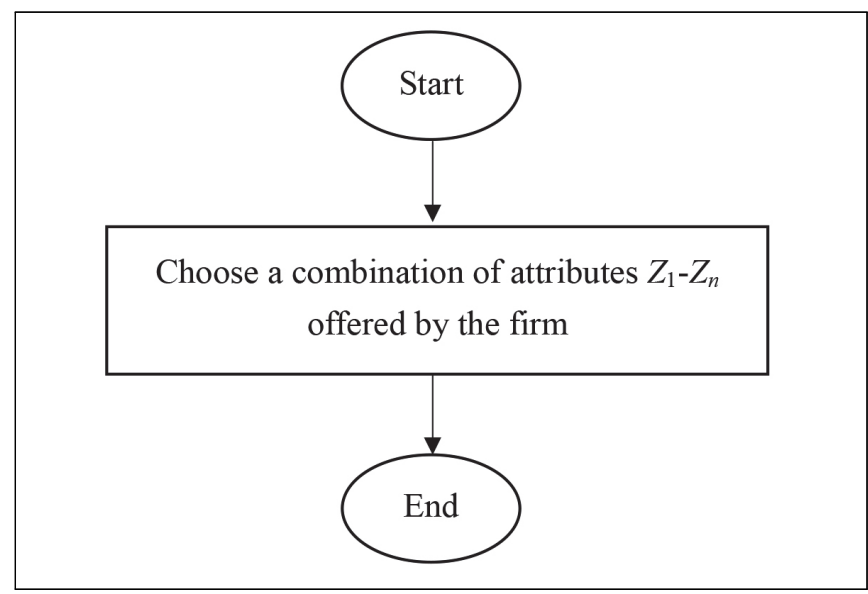


〈Figure 2〉AbA (Attribute-by Attribute) Customization System

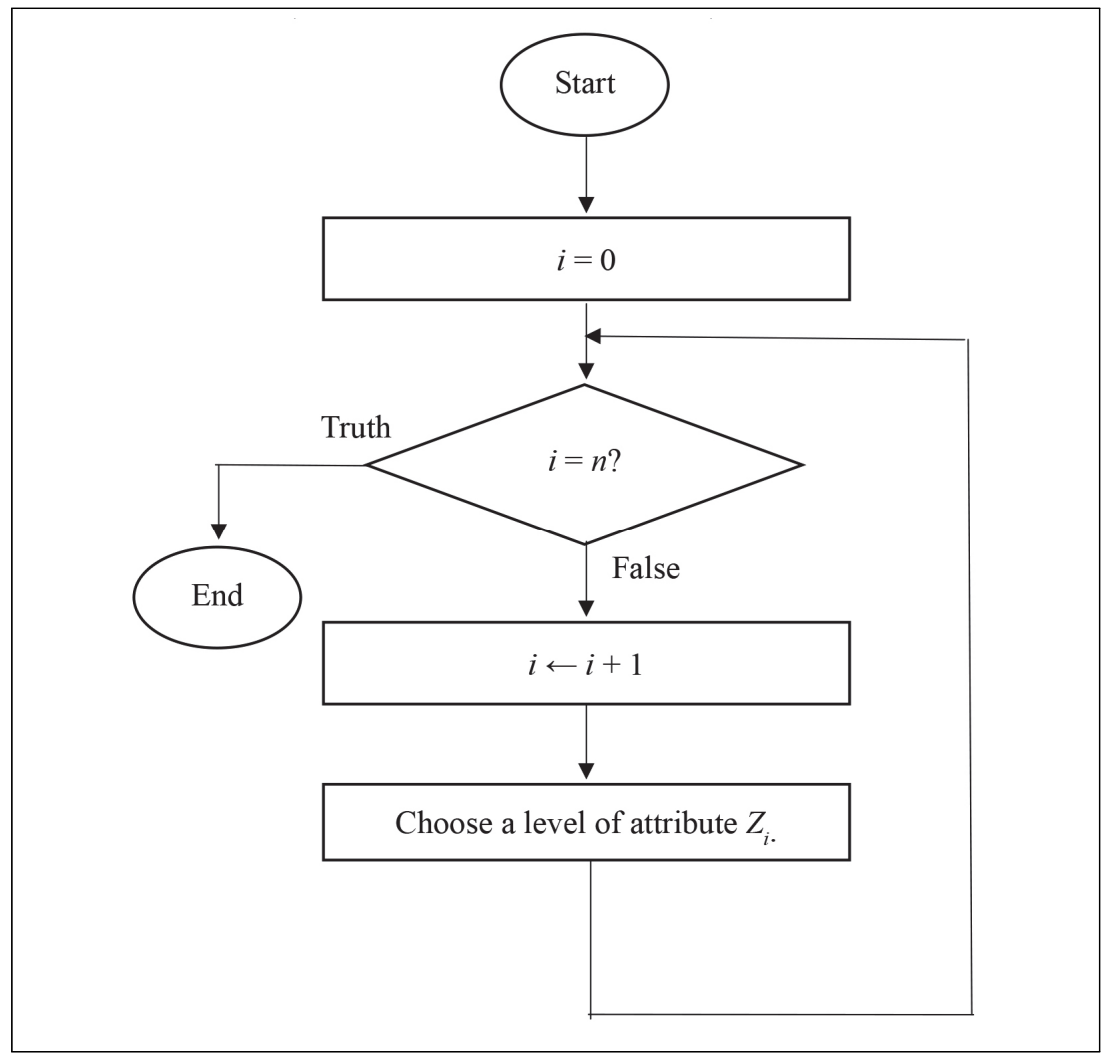

in which customers do not choose a product or, in other words, a combination of $Z_{1}-Z_{n}$, and choose $Z_{1}-Z_{\mathrm{n}}$, one by one. For example, customization systems, provided by personal computer manufacturers in the 1990s are typically AbA systems, by which customers choose attributes, such as CPU clock rate, memory capacity, and hard disk space individually.

Figure 3 represents a relatively new customization system called the CvSS (customization via starting solutions) system (Hildebrand, Häubl, and Herrmann 2014). The CvSS system is characterized, of course, by starting solutions, each of which is a combination of attributes $Z_{1}-Z_{n}$ offered by the firm. After choosing a certain combination of $Z_{1}-Z_{n}$ as a starting solution, customers determine whether they need to change each of $Z_{1}-Z_{n}$, and change some of these product attributes if they wish. For example, in customization systems recently provided by PC manufacturers, customers choose a model from some combinations of attributes (e.g., CPU clock rate, memory capacity, and hard disk space) initially offered by the manufacturers, and then modify the model by changing certain attributes. It should be noted that cus- 
〈Figure 3〉 CvSS (Customization via Starting Solutions) System

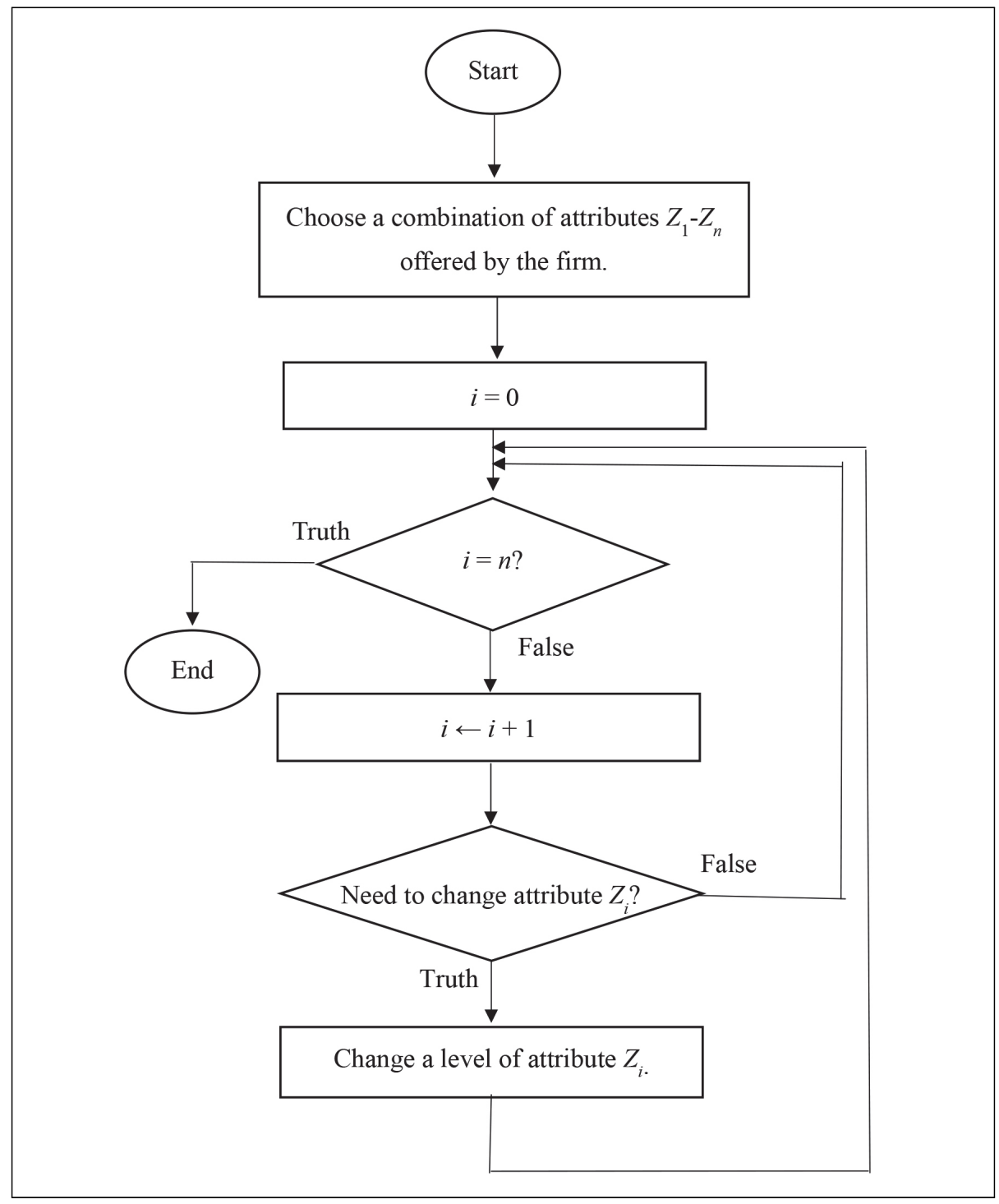

tomers can omit changing (choosing) some attributes and, therefore, the total number of times customers choose (change) the level of product attributes in the CvSS system can be smaller than that in the AbA customization system. That implies that in the CvSS system, customer sat- isfaction in relation to customization might be higher because less effort is required, as emphasized by Hildebrand, Häubl, and Herrmann (2014).

Our new customization system, called the CvWS (customization via waypoint solutions) 
〈Figure 4〉 CVWS (Customization via Waypoint Solutions) System

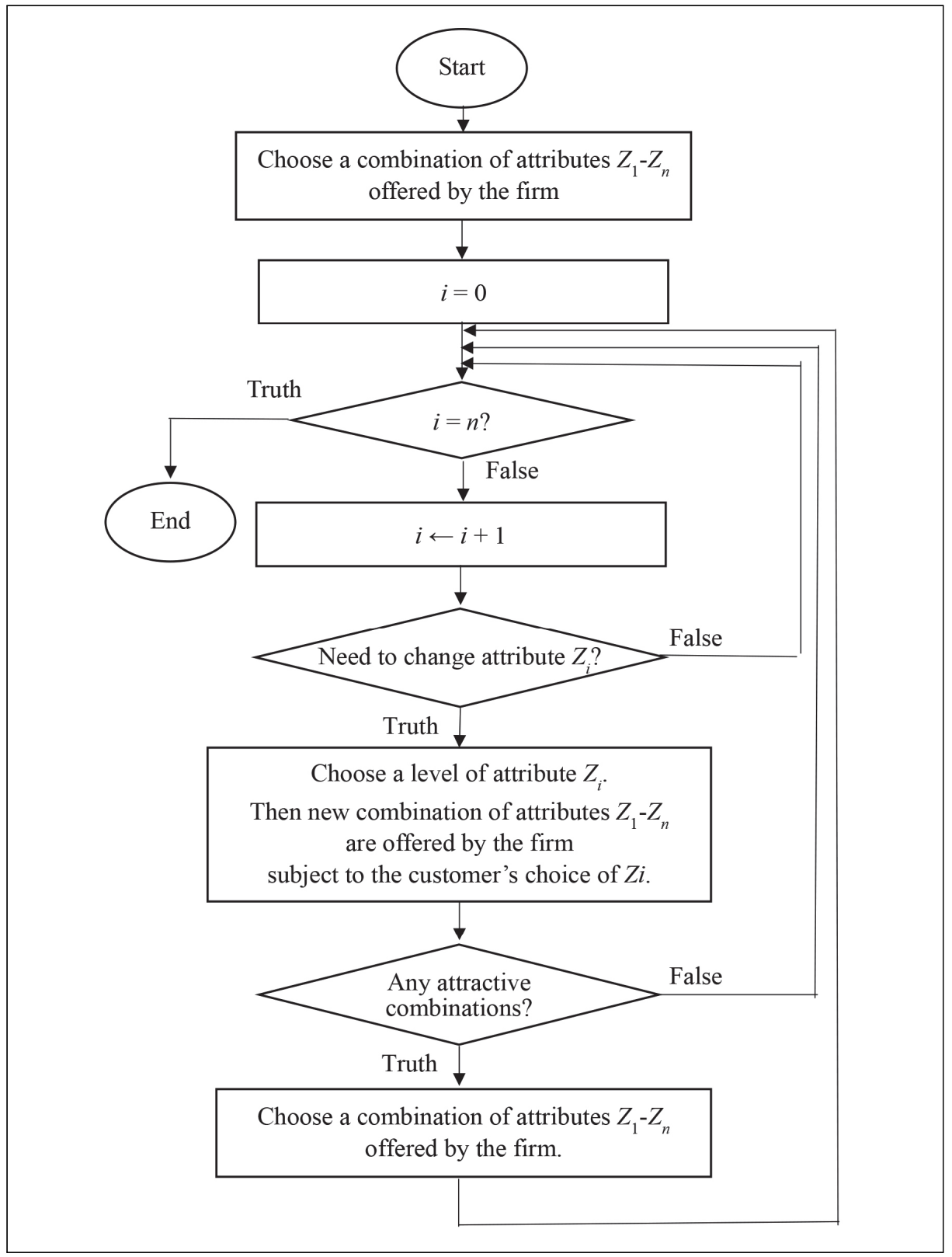

system can be modeled as Figure 4. After choosing a starting solution, if customers wish to modify some attributes of the starting solution and, in fact, change a level of an attribute, $Z_{i}$, then the firm offers new combinations of attributes or, in other words, waypoint solutions. 
While starting solutions are products in which all attribute levels are randomly offered by the firm, waypoint solutions are products in which the levels of certain features are fixed as the customer changes and only the levels of the remaining attributes are different. Once offered solutions are renewed, two options are available for the customers: one is to continue to change/ not change the levels of attributes; the other is to choose one of the new solutions offered by the firm, which can, in turn, reduce the level of customer effort required to complete the customization.

In the same way as starting solutions, waypoint solutions can help to reduce the number of times customers change the level of the remaining product attributes. Therefore, the CvWS system is superior, even to the CvSS system, in reducing the customer effort required to complete customization and, thus, improves customer satisfaction with customization.

\section{Examination of Feasibility: Surrogate Constraint Method}

It should be noted, however, that waypoint solutions cannot reduce customer effort if the newly offered solutions are not more attractive than older solutions, including the starting solutions. This is in contrast to starting solutions, which can be randomly offered without any consideration of what the optimal set of solutions would be (Hildebrand, Häubl, and Herrmann 2014). In order to make waypoint solutions attractive, the firm should analyze the optimal levels of the remaining attributes based on each customer's choice in relation to particular attributes.

How can firms make waypoint solutions optimal? The question is related to a so-called "knapsack problem"- the nonlinear multi-objective discrete optimization problem. Many solutions for knapsack problems have been proposed and applied in a wide variety of research fields in marketing, such as stratified sampling (Hughes and Rao 1979), sales resource allocation (Zoltners and Sinha 1980), catalog planning (Armstrong, Sinha and Zoltners 1982), production planning (Ziegler 1982), and layout problems in the fashion industry (Degraeve and Vandebroek 1998), but solving a knapsack problem is still regarded as particularly problematic. In this section, we examine the feasibility of the CvWS system in terms of how firms optimize waypoint solutions using a novel method for solving the nonlinear knapsack problem.

The knapsack problem is a combinatorial optimization issue-given a set of items, each of which has a particular size or value, the number of each item, including in a combination (knapsack), should be determined so that the total size is less than or equal to a given limit and the total value is as large as possible. The nonlinear knapsack problem is one in which the objective functions cannot be explained in a linear equation. This has been recognized as 
one of the most difficult optimization problems.

The nonlinear knapsack problem was first treated in the literature of IEEE's reliability engineering field (Moskowitz and McLean 1956; Mine 1959). However, researchers in the field utilized the heuristic solution and few researchers have utilized an exact solution approach because it becomes more difficult to solve the problem as the scale becomes larger. As an exception, Glover (1968) developed the surrogate constraint method as a solution for the multiple constraint problem. His method is characterized by the idea of giving a weight to each constraint (surrogate multiplier) and combining multiple constraints into a single constraint (surrogate constraint). His algorithm is useful only for linear knapsack problems. Its application does not provide a solution to nonlinear problems. To overcome this problem, Nakagawa and his colleagues have tried to improve Glover's surrogate constraint method.

Nakagawa (2003) improved Glover's method and succeeded in providing all optimal solutions around the duality gap, and proved that they are exact solutions. Following Nakagawa (2003), Isada, James, and Nakagawa (2005) proved the practicality of the improved surrogate constraint method by utilizing this method to nonlinear multi-objective separable discrete optimization problems with one constraint. Finally, Nakagawa, James, Rego, and Edirisinghe (2014) further improved the surrogate constraint method by utilizing the concept of information theory (Shannon
1948) and proposed the improved surrogate constraint method with entropy (ISCENT).

As such, knapsack problems with several constraints and over a thousand variables, long regarded as unsolvable, can now be resolved successfully through the recent improvement in algorithm technology development by Nakagawa and his colleagues.

Customers, who have a wide variety of preferences, have several different evaluation criteria for the utility of a product. For satisfying these needs, one preferable solution, maximizing the gross utility, would not be identified. Rather, the Pareto-optimal solution, which maximizes the gross utility for certain criteria and does not maximize the gross utility of other criteria, would be identified. In this instance, Nakagawa's ISCENT (improved surrogate constraint method with entropy) (2014) can be utilized to identify the Pareto-optimal solutions and eliminate the combinations of the levels of attributes that are not included in the suggested lists of optimal combinations because no customers would be attracted to them.

\section{Conclusion}

In this paper, we proposed a new customization configuration system called the CvWS (customization via waypoint solutions) system, and compared it to two existing systems, the 
AbA (attribute-by-attribute) customization system and the CvSS (customization via starting solutions) system.

Firms may want to provide customized products when they have the potential to provide a wide variety of products with different product configurations and/or their customers have a wide variety of needs. However, they should continue to provide mass-produced standardized products if they fail to provide a customization configuration system that requires little effort on the part of customers to complete the process.

In this regard, the AbA customization system forces customers to choose the levels of all product attributes and, therefore, the amount of effort that customers need to complete the customization configuration process is high. It is certain that, with the CvSS system, firms can assist their customers to some extent by offering a set of starting solutions. Customers may complete their customization process more easily as all they have to do is to choose (change) a relatively small number of product attributes. Therefore, the amount of customer effort may be lower than that in the AbA customization system. However, the CvSS system only allows firms to assist their customers at the beginning of the process.

Therefore, in this paper, CvWS was proposed. By offering not only a set of starting solutions at the beginning but also a set of waypoint solutions on each occasion that customers choose (change) any product attributes, the firm can assist customers in the entire customization configuration process. Because the number of product attributes that customers have to choose (change) is smaller than that in the CvSS system, the amount of customer effort may be lower and the degree of customer satisfaction may be higher in the CvWS system.

It should be noted that, as mentioned by Hildebrand, Häubl, and Herrmann (2014), starting solutions may not need to be optimized whereas waypoint solutions should be optimized based on each customer's action to modify the previous solution by changing the levels of one or more product attributes. Consequently, firms cannot utilize the CvWS system unless waypoint solutions are optimized. Regarding the optimization problem, we discussed that waypoint solutions can be Pareto-optimized using our improved surrogate constraint method with entropy (ISCENT) (Nakagawa, et al. 2014). Thus, with the newly proposed system, more firms should consider providing a wide variety of customized products instead of mass-produced standardized products.

In future research, our CvWS should be further investigated in terms of how low is the customer effort required for customization and how high is customer satisfaction toward the customization, compared with the CvSS system. Previous research has measured the amount of effort and the degree of satisfaction based on laboratory experiment and psychological scaling and compared the CvSS system with the AbA 
customization system (Hildebrand, Häubl, and Herrmann 2014). By referring to these studies, it may be fruitful to compare the new CvWS system with the CvSS system.

〈Received December 25. 2015〉

〈Revised April 6. 2016〉

$\langle$ Accepted April 6. 2016〉

\section{References}

Dellaert, Benedit G. C. and Stefan Stremersch (2005), "Marketing Mass-customized Products: Striking a Balance Between Utility and Complexity," Journal of Marketing Research, 42 (May), 219-27.

Duray, Rebecca (2002), "Mass Customization Origins: Mass or Custom Manufacturing?" International Journal of Operations and Productions Management, 22 (3), 314-28.

Flynn, Anthony and Emily Flynn Vencat (2012), Custom Nation: Why Customization is the Future of Business and How to Profit From It, Dallas, TX: BenBella Books.

Glover, Fred (1968), "Surrogate Constraints," Operations Research, 16 (July-August), 741-49.

Hoch, Stephan J., Eric T. Bradlow, and Brian Wansink (1999), "The Variety of an Assortment," Marketing Science, 18 (4), 527-46.

Huffman, Cynthia and Barbara E. Kahn (1998), "Variety for Sale: Mass Customization or
Mass Confusion," Journal of Retailing, 74 (Autumn), 491-513.

Hildebrand, Christian, Gerald Häubl, and Anderses Herrmann (2014), "Product Customization via Starting Solutions," Journal of Marketing Research, 51 (December), 707-25.

Isada, Yuriko, Ross J. W. James, and Yuji Nakagawa (2005), “An Approach for Solving Nonlinear Multi-objective Separable Discrete Optimization Problem with One Constraint," European Journal of Operational Research, 162 (April), 503-13.

Kumar, Ashok (2004), "Mass Customization: Metrics and Modularity," International Journal of Flexible Manufacturing Systems, 16 (December), 287-311.

Kurniawan, Sri Hartati, Richard H.Y. So, and Mitchell M. Tseng (2006), "Consumer Decision Quality in Mass Customization," International Journal of Mass Customization and Personalization, 1 (2/3), 176-94.

Liechty, John, Venkatram Ramaswamy, and Steven H. Cohen (2001), "Choice Menus for Mass Customization: An Experimental Approach for Analyzing Customer Demand with an Application to a Web-Based Information Service," Journal of Marketing Research, 38 (May), 183-96.

Mine, Hisashi (1959), "Reliability of Physical System," Transactions International Symposium Circuit and Information Theory, 5, 138-51.

Moskowitz, Fred and John W. McLean (1956), 
"Some Reliability Aspects of System Design," IRE Transactions on Reliability and Quality Control, PGRQC-8, 7-35.

Nakagawa, Yuji (2003), “An Improved Surrogate Constraints Method for Separable Nonlinear Integer Programming," Journal of the Operations Research Society of Japan, 46 (2), $145-63$.

Ross J. W. James, César Rego, and Chanaka Edirisinghe (2014), "EntropyBased Optimization of Nonlinear Separable Discrete Decision Models," Management Science, 60 (May), 695-707.

Ogawa, Susumu and Frank T. Piller (2006), "Reducing the Risks of New Product Development," MIT Sloan Management Review, 47 (Winter), 65-71.

Ramdas, Kamalini (2003), "Managing Product Variety: An Integrative Review and Research Directions," Production and Operations Management, 12 (Spring), 79-101.

Randall, Taylor, Christian Terwiesch, and Karl T. Ulrich (2005), "Principles for User Design of Customized Products," California Management Review, 47 (Summer), 68-85.

Shannon, Claude E. (1948), "A Mathematical Theory of Communication," Bell System Technical Journal, 27 (July), 379-423.

Shapiro, Carl and Hal R. Varian (1999), Information Rules: A Strategic Guide to the Network Economy, Boston, MA: Harvard Business School Press.

Simonson, Itamar (2005), "Determinants of Customers' Responses to Customized Offers: Conceptual Framework and Research Propositions," Journal of Marketing, 69 (January), 32-45.

Valenzuela, Ana, Ravi Dhar, and Florian Zettelmeyer (2009), "Contingent Response to Self-Customization Procedures: Implications for Decision Satisfaction and Choice," Journal of Marketing Research, 46 (December), 754-63.

Zipkin, Paul (2001), "The Limits of Mass Customization," MIT Sloan Management Review, 42 (Spring), 81-87. 